\title{
Bringing symmetry between and within safety and security cultures in high- risk organizations
}

\author{
Colin Glesner $^{\mathrm{a}, \mathrm{b}, *}$, Michiel Van Oudheusden ${ }^{\mathrm{a}, \mathrm{c}}$, Catrinel Turcanu ${ }^{\mathrm{a}}$, Catherine Fallon ${ }^{\mathrm{b}}$

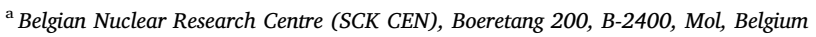 \\ ${ }^{\mathrm{b}}$ Université de Liège, SPIRAL Research Centre, Place XX Aout, B-4000 Liège, Belgium \\ ${ }^{\mathrm{c}}$ University of Cambridge, Department of Sociology, 16 Mill Ln, CB2 1SB Cambridge, United Kingdom
}

\section{A R T I C L E I N F O}

\section{Keywords:}

Safety culture

Security culture

Co-production

Actor-Network Theory

High-risk organizations

\begin{abstract}
A B S T R A C T
Based on a review of scholarly, regulatory and policy literatures, this article illustrates how 'safety culture' and 'security culture' are conventionally understood within the context of high-risk organizations. It identifies two important recurring gaps in the literature: (1) the subordination of the analysis of security culture to safety culture concepts, and (2) the anthropocentricity inscribed in both notions, which sideline the dynamic interplay between social and technical elements in the constitution of 'culture'. To address these gaps, the article introduces concepts and heuristics from Science and Technology Studies, specifically co-production and ActorNetwork Theory. Using the concrete examples of the labelling of hazardous materials and the "four eyes" principle, it highlights how these heuristics may open onto a more symmetrical analysis of safety and security cultures in high-risk contexts. It thereby seeks to make visible the mutual shaping of safety and security cultures and attend to the roles of non-human actors as active participants in such processes.
\end{abstract}

\section{Introduction}

Contemporary technological societies face an increasing number of crises, such as environmental catastrophes, technological and industrial disasters, and terrorist attacks (Bijker et al., 2014). These crises may have non-malevolant human or natural causes, can be rooted in intentional and malevolent acts, or comprise a mix of motivations and behaviors (Khripunov \& Kim, 2008). Particularly vulnerable to these growing threats are organizations in hazardous industries such as the nuclear industry. In order to prevent and mitigate the risks confronting them, these organizations have developed measures to enhance first and foremost their safety, and more recently, their security. This evolution is reflected in the institutional (e.g. policy, business organizational and regulatory documentation) and academic literature, notably on organizational culture and in the concepts of safety culture and security culture, which give consideration to human and cultural impacts on safety and security (Antonsen, 2009). The two concepts have received unequal attention over time, both from policymakers and scholars (Argenti et al., 2015; Directive 2012/18/EU, 2012).

Safety culture, inspired by the concept of organizational culture, became an overriding priority in the 1980 's. The Chernobyl accident (1986) and the summary report of the International Nuclear Safety Advisory Group (IAEA, 1986) that followed triggered substantial scientific research and discussion on what safety culture entails. The concept was further developed in the 1990's and early 2000's (Choudhry et al., 2007; Cooper, 2000; Guldenmund, 2000; IAEA, 1991; Pidgeon, 1991). As we illustrate below, amid the large number of works that emerged, there is considerable variation in how the term is understood and applied, which raises challenges for the use and operationalization of the concept (Antonsen, 2009; Choudhry et al., 2007; Cooper, 2000, 2016; Gilbert et al., 2018; Guldenmund, 2018, 2000; Haukelid, 2008; Henriqson et al., 2014; Hopkins, 2016; Le Coze, 2019).

The notion of security culture gained traction only in the 2000 's, in the aftermath of terrorist attacks such as 9/11 (Argenti et al., 2015, p. 170; Reniers et al., 2011, p. 1242). Debates about the concept of security culture are primarily situated in the nuclear field and were first initiated and mainly organized by the International Atomic Energy Agency (IAEA, 2001, 2016b). Studies by Jore, Malcolmson and Reniers et al. in various areas have highlighted that the IAEA's definition has remained largely unchallenged in the academic literature (Jore, 2016; Malcolmson, 2009; Reniers et al., 2011).

As security culture was not developed as a concept in its own right but mostly transposed from literatures on safety culture, there is a lack of understanding about the specific conceptual evolution of security culture and its relationship to safety. This blind spot has potentially farreaching practical implications for organizations in hazardous

\footnotetext{
* Corresponding author at: Belgian Nuclear Research Center (SCK CEN), Boeretang 200, B-2400 Mol, Belgium.

E-mail address: cglesner@uliege.be (C. Glesner).
} 
industries, raising questions such as: What are safety culture and security culture composed of? How are safety culture and security culture characterized? How do they interact? How can they be analyzed in practice? This represents the first gap this paper addresses.

A second gap revealed in the literature concerns the scope and depth of prevalent definitions of 'culture.' The research on safety culture and security culture has tended to singularly focus on anthropocentric elements in safety and security without considering, or accounting for, non-human aspects (Rollenhagen, 2010). Conceptions of both safety culture and security culture largely ignore or fail to recognize how nonhuman elements or actors (e.g., security cameras, fingerprints systems, evacuation doors, incident reporting system) constitute and enact individual, group, and organizational cultures. Even studies that extend the analysis of safety and security cultures to include procedures, technologies or artifacts do not consider these as active and symmetric components of the two cultures (Glendon \& Stanton, 2000; Grote \& Künzler, 2000; Guldenmund, 2007, 2000; Naevestad, 2009; Pidgeon, 1998; Reniers et al., 2011; Yoo \& Lee, 2015). Symmetry represents here a methodological precept taken from Actor-Network Theory (ANT), and implies that no a priori distinction is made between human actors and non-human actors in the construction of safety and security. Instead, it acknowledges that both humans and non-humans participate in shaping and performing both cultures; a point to which we turn below.

Taking these gaps as entry points for analysis and reflection, this article combines and discusses concepts and approaches developed in the burgeoning, interdisciplinary field of Science \& Technology Studies (STS), specifically co-production and ANT (Akrich et al., 2013; Callon, 1985; Jasanoff, 2004; Joly, 2015; Latour, 2005). Co-production especially focuses on the mutual shaping and co-construction of knowledge and social orders (Jasanoff, 2004; Joly, 2015) and ANT illuminates the interactions between humans and non-humans in a symmetrical and relational manner. As we illustrate in this paper, mobilising these approaches facilitates consideration and development of mutually informed understandings of safety culture and security culture. Moreover, they open up questions about what is at stake in safety and security, how these principles operate, and how they are enacted in practice.

By analyzing the literature and discussing what the two STS approaches could bring to safety and security cultures this article provides a theoretical and conceptual frame which can bring innovative insights regarding safety and security cultures in organizations in hazardous industries. While an in-depth empirical analysis is beyond the scope of the current paper, we provide two examples to illustrate the potential of the newly developed frame for scholars, policymakers and various practitioners working in hazardous contexts, thus paving the way for further analyses.

In what follows, we first illustrate how safety and security cultures are understood in policy, business-organizational and academic literatures and describe in more details the two aforementioned gaps (section 2). Building on our review, the third section presents the theoretical frameworks discussed in this paper and suggests useful tools for their application to the study of safety and security cultures. The fourth section addresses the two identified gaps by applying co-production and ANT for the analysis of real-world enactments of safety and security cultures. Our article is meant as a contribution to further research on safety and security cultures, which usefully problematizes and 'opens up' these concepts by bringing STS thinking into the safety-security equation.

\section{Safety and security cultures analysis: Variations and consistency}

In this section, we use the technique of purposeful sampling to analyze the research on safety and security cultures in view of how these cultures have been addressed by scholars and practitioners over time. Adopting the principle of 'maximum variation', we analyzed institutional and academic manuscripts covering an extensive time range (from 1970's until present), with a focus towards including a diversity of understandings, definitions and implementations in our sample (Harsh, 2011). Our analysis highlights consistent gaps in current literatures.

\subsection{Dominant notions of safety culture}

The concept of safety culture was initially shaped through research on organizational culture (Antonsen, 2009). Among the seminal works in this area, Schein's book, "Organizational culture and leadership" published in 1985, especially influenced the first development of the safety culture concept (Fucks, 2004). Schein describes organizational cultures as a stable, constructed and multidimensional set of assumptions, values and behaviors shared within an organization; it protects employees against the unknown and unwanted as it creates regularities in behaviors (Schein, 1985). In its seminal INSAG-4 report published in the aftermath of the 1986 Chernobyl nuclear power plant accident, the International Atomic Energy Agency (IAEA, 1991) influenced by Schein's work, characterizes the concept as: "that assembly of characteristics and attitudes in organizations and individuals which establishes that, as an overriding priority, nuclear plant safety issues receive the attention warranted by their significance" (IAEA, 1991, p. 4). This definition builds on the IAEA's conception of safety:

"the protection of people and the environment against radiation risks, and the safety of facilities and activities that give rise to radiation risks. 'Safety' [...] includes the safety of nuclear installations, radiation safety, the safety of radioactive waste management and safety in the transport of radioactive material; it does not include non-radiation-related aspects of safety." ( IAEA, 2016, p. 155; IAEA, 2007; Koenick, 2011).

As it followed from conceptual groundwork around the concept of organizational culture, safety culture literatures strongly emphasized the 'culture' component of safety and paid less attention to that of 'safety' (Antonsen, 2009; Rollenhagen, 2010). Only a few definitions of 'safety' were proposed, giving the impression of conceptual convergence. However, among the definitions analyzed, at least two contending visions can be portrayed (Antonsen, 2009; Edwards et al., 2013; Hessami, 2004; IAEA, 2016a; Koenick, 2011; OECD, NEA, FSC (2013); Rochlin, 1999; Rollenhagen, 2010; Slovic, 1992). The first view, which is presently dominant in the literature, sees safety as the opposite of posing risks. It reflects a static or passive vision of safety, as the "freedom from harm to people caused by unintentional or random/systematic events." (Hessami, 2004, p.100); or as the "freedom from any unacceptable risk of harm"(Schnieder et al., 2009, p. 6)

A second, more active vision of safety, argues that safety is enacted through the interaction of a multiplicity of elements:

"The presence of material, symbolic and immaterial arrangements and conditions (technological, norms, administrative, social, etc.) which have the function to dynamically cope with direct and indirect real or potential hazards which may result in negative consequences." (Rollenhagen, 2010, p. 270)

This view aligns with the high reliability organization and resilience engineering literatures, the concept of Safety-II as proposed by Hollnagel, as well as the work around complex systems carried out by Dekker (Dekker, 2011; Hollnagel, 2014). ${ }^{1}$

In contrast to the little attention given to the concept of safety, a

\footnotetext{
${ }^{1}$ Hollnagel refers to the dominant vision of safety as Safety-I. This vision is accident-centered, as it concerns itself with the absence of safety and asks why things go wrong. In contrast, Safety-II centers on explaining why things go right and why accidents do not occur. This shift in focus invites us to consider how safety is enacted through the daily performance of elements that together compose a dynamic system, rather than seeing safety as a fixed state. Following this, safety is according to him summarized as a dynamic-event.
} 
multitude of scientific studies and policy documents have sought to define and further develop the concept of safety culture. Despite several decades of reviews and conceptual analyses, a large variation of understandings and a certain fuzziness still remains around the concept of safety culture (Cooper, 2016; Edwards et al., 2013; Guldenmund, 2018; Haukelid, 2008; Hopkins, 2016; Le Coze, 2019). Definitions proposed by academic and institutional literatures indeed formulate multiple terms and characterizations. For instance, Cox and Cox's (1991) definition of safety culture mobilizes concepts such as 'attitudes', 'beliefs', 'perceptions' and 'values'. Richter and Koch (2004) stress 'meanings', 'experiences' and 'interpretations'. The U.S. Nuclear Regulatory Commission distinguishes 'values', 'behaviours' and 'collective commitment' as key features (NRC, 2018). Henriqson and colleagues see safety culture as an object of knowledge which "encapsulates consensual values, beliefs, and behaviours in relation to risk and safe behavior" (Henriqson et al., 2014, p. 469). Furthermore, whereas some definitions focus on safety culture as a set of actions and behaviors, others emphasize perceptions. Next to this variety of terms, little agreement exists concerning the enactment and the implementation of safety culture. While some scholars see safety culture as something shared by a group of employees inside an organization (Cox \& Cox, 1991), others refer to collective elements of an organization that guide people's actions (Richter \& Koch, 2004). Moreover, while some are centered on safety, others open safety culture for broader elements such as organizational aspects or objectives like quality, costs and production (Henriqson et al., 2014). In short, although the term is widely recognized and used in the literature, "safety culture" covers different ranges or extents (Antonsen, 2009; Cooper, 2016; Guldenmund, 2018; Hopkins, 2016; Le Coze, 2019).

This breadth of meanings, definitions and views, partly owing to its roots on organizational culture, raises challenges for the comprehension and operationalization of safety culture concepts, especially in an organizational context (Edwards et al., 2013; Gilbert et al., 2018; Guldenmund, 2018; Haukelid, 2008; Henriqson et al., 2014; Hopkins, 2016; Le Coze, 2019). Even though some scholars have recently proposed new classifications (Antonsen, 2009; Edwards et al., 2013; Henriqson et al., 2014) or criticized the very existence of the concept (Hopkins, 2016, 2018), a conceptual dichotomy opposing functionalist and interpretive approaches which developed during the period between the 1990's and 2000, analyzed as the safety culture 'first wave' by Le Coze (2019) and referred to as the "safety culture peak" by Cooper (2016), still remains pivotal for understanding the roots of this variation.

Without going into full details we attempt here to capture the main tenets of this still influential debate.

The functionalist perspective engenders a managerial, instrumental and top-down approach to culture. It sees 'culture' as a set of behaviors, attributes, processes or policies assuring that safety remains an overriding priority. In this view, culture is something that an organization has. The culture's primary function is to support management ideology, goals and strategies. Assessment tools to this end typically include quantitative methods such as surveys (Huang et al., 2007; Lee \&
Harrison, 2000), as well as qualitative methods such as observations and interviews (IAEA, 2008b). Scholars assessing safety culture from a functionalist perspective tend to view safety as an ideal that can be managed by way of prediction and control models (Bernard, 2014; Cooper, 2000; Glendon \& Stanton, 2000). In this top-down perspective, safety culture is derived from risk and safety management strategies developed by management, and focuses on macro phenomena (Naevestad, 2009). In her literature review, Fucks (2004) illustrates these functionalist characteristics by using the IAEA definition of safety culture (1991, p. 4) (quoted above) as an example. First, the IAEA definition suggests that there is no pre-existing safety culture in an organization; rather, safety has to be instituted from above. Second, safety is formally constructed through the actions of management, without due attention to informal safety culture. Third, an organization is understood to have one culture rather than many. Overall, the functionalist perspective is dominant in organizational and safety studies; and it is mobilized by a wide range of authors working in these fields (Cooper, 2016; Cox \& Flin, 1998; Furnham \& Gunter, 2015; Harvey et al., 2002; Hofstede, 1994; Kono, 1990; Lee \& Harrison, 2000; Lundberg, 1990; Reason, 1998).

The interpretive perspective (also called interpretative), influenced by the works of anthropologists such as Geertz, Keesing and Bloch (Bloch, 1998; Geertz, 1993; Keesing, 1987, 1994 retrieved from Haukelid, 2008), views culture as something an organization is or does (Henriqson et al., 2014). Culture emerges through ongoing, complex interactions within groups "serving as prime medium for all members of an organization to interpret their collective identity, beliefs and behaviors" (Glendon \& Stanton, 2000, p. 194). A culture is produced by all individuals within an organization through bottom-up, local and situated interactions. Safety culture is therefore seen as a consequence. The focus in this perspective is on micro phenomena within organizations. Hence, it suggests that safety culture cannot be characterized with generic features; instead, it has to be assessed through complex descriptions of work activities and contextual components. This perspective argues that any attempt to a rapid change of an organization's culture carried out by the management in a top-down fashion is unlikely to succeed as the model extoled will not readily align with the interactions at work: "culture cannot be managed; it emerges. Leaders don't create cultures; members of the culture do. [...] It is naïve and perhaps unethical to speak of managing culture" (Martin, 1985 retrieved from Haukelid, 2008, p. 417). Consequently, such a perspective more easily allows for the existence of multiple, partially overlapping sub-cultures related to specific groups and aligned on team borders in an organization, which may sometimes conflict with one another and with management strategies (Fucks, 2004; Haukelid, 2008; Krackhardt \& Kilduff, 1990; Pidgeon, 1998; Tompson \& Mchugh, 2002). These approaches typically mobilize triangulated and qualitative methods, such as ethnographies and participant observation, to investigate the contextual features of safety culture. Table 1 provides a comparative overview of these two conceptions on safety and security cultures.

Table 1

A comparative overview of the dichotomy the functionalist and interpretive perspectives of safety and security cultures.

\begin{tabular}{ll}
\hline Functionalist perspective & Interpretive perspective \\
\hline Managerial perspective (top-down) & Contextualized perspectives (bottom-up) \\
Culture is constituted by management & Cultures precedes attempts to produce one \\
Culture is a component of what an organization has & Cultures are an embodiment of what an organization is/does \\
Culture is a cause & Culture is a consequence \\
Culture is unique & Culture are multiple and potentially opposing \\
Safety as an ideal rationally modelled & Safety as the result of complex interactions \\
Assessed through quantitative and qualitative methods & Assessed through qualitative methods \\
Focuses on global strategies (macro-phenomena) & Focuses on local and situated interactions (micro-phenomena) \\
Anthropocentric perspective & Anthropocentric perspective
\end{tabular}




\subsection{From safety culture to security culture}

Despite the growing prominence of security issues, security culture has received far less scholarly attention than safety culture, and this for a number of reasons. The first is that the concept of security culture emerged fairly recently, in the aftermath of the 9/11 terrorist attacks. The second is related to the historically minor demand from hazrdous industries, which for a long time considered the intentional and malicious risk to be relatively small, if not insignificant (Reniers et al., 2011, p. 1242). The third is that security was first analyzed through the lens of geopolitics and defense security (Burgess et al., 2018), while organizational security has only recently come into focus (Jore, 2019). This element touches on the perceived confidential character of security, mostly dealt with by homeland and foreign security, with only a few people in charge of maintaining security in organizations (Jore, 2017).

Taken together, these elements help explain why the literature on security remained within the defense and intelligence scope, and why academic and policy developments in the organizational field introduced the dimension of security within the already developed concept of safety culture. This subjection of security culture to safety culture represents the other literature gap this paper addresses. Such a subordination is to be observed through a number of elements we develop below and is mainly observable through the absence of further development of the concept of security culture and the emphasis on the synergies between safety and security (Flory, 2013). As Jore highlights it, this concept needs further analysis of its specificities in order to get a grasp on its interplay with safety culture (2017). 2001:

The first definition of security culture was proposed by the IAEA in

"Security culture includes characteristics and attitudes in organizations and of individuals which establish that protection against the loss, theft, or other unlawful taking of nuclear material, on the one hand, and deliberate malicious acts against nuclear facilities or during transport of nuclear materials, on the other, receive the attention warranted by their significance" (IAEA, 2001).

Although it addresses different risks, this definition relies on that of safety culture. It also led to the characterization of nuclear security as "the prevention and detection of, and response to, theft, sabotage, unauthorized access, illegal transfer or other malicious acts involving nuclear material, other radioactive substances or their associated facilities." (IAEA, 2008, p.3). It is replicated in subsequent IAEA documents (for example: IAEA, 2009, p. 3, 2016a, p. 155), and in further academic research on security culture (Batra \& Nelson, 2012; Gandhi \& Kang, 2013; Yoo \& Lee, 2015).

Definitions of security in the organizational context which are found in academic and policy literatures reveal the same dichotomy encountered for safety, namely between passive and active perceptions. For example, the Society for Risk Analysis (SRA) defines security as:

"The antonym of risk when restricting the concept of risk to intentional acts by intelligent actors (the security level is linked to the risk level, a high security level means a low risk and vice versa)"(Aven et al., 2015).

Opting for an active perspective, Jore (2017a, p. 855) proposes a definition emphasizing the interaction of several elements: "Security can be defined as the ability to prepare for, adapt to, withstand and recover from danger and crises caused by people's deliberate, intentional and malicious acts such as terrorism, sabotage, organized crime and hackers."

In contrast with the concept of security, only a few alternative definitions of security culture have been developed. Some studies (Jore, 2016; Malcolmson, 2009; Reniers et al., 2011) have attempted to review and define security culture, yet, as Malcolmson (2009) highlights in his study on aviation security, there is presently no operable security culture definition that works in an organizational context. Reniers and colleagues (2011) come to a similar conclusion and to fill this gap, propose a definition of security culture applicable to the chemical industry:

"security culture in a chemical plant is the extent to which workers within the organizational premises (e.g. plant employees, contractors) regard security as important and the beliefs about how (physical, electronic, organizational, etc.) security should be executed, bearing in mind that hazardous substances are being handled in large quantities in the plant. These values and beliefs will evolve into certain norms about how to handle chemical company security." (p. 1242).

The work of Reniers et al. (2011) is one of the first attempts to integrate safety and security cultures; potentially in alignment with international institutional imperatives to further integrate safety and security concepts and methods (IAEA, 2016a, 2016b; The Hague Nuclear Security Summit, 2014). It also resonates with integrative safety-security approaches found in the literature (Aven, 2007; Gandhi \& Kang, 2013; Hahn, 2011; Khripunov \& Kim, 2008; Kim \& Kang, 2012). However, Reniers et al.'s work also raises problems and questions. First, the definitions of safety and security cultures are not mutually informed; i.e., the concepts do not account for the mutual shaping of the two cultures. Second, their conceptualization provides a managerial or top-down vision of culture (grounded in functionalist perspective), which insufficiently takes into account bottom-up enactments (highlighted in interpretive perspectives).

\subsection{An anthropocentric focus}

Although the functionalist and interpretive perspectives represent different, by and large opposing, views of safety culture (and by extension, security culture), they do share a common feature: both have an anthropocentric focus of safety culture, which is oblivious to the role of non-human actors in the construction of culture. As Rollenhagen argues, safety culture remains "basically a people oriented concept" (Rollenhagen, 2010, p. 270), which fails to account for the role of nonhumans as constitutive element of safety culture.

As illustrated in section 2.1 above, scholars associate culture with individual or group traits, such as 'beliefs', 'perceptions', 'attitudes', 'values', and 'behaviors', leaving little to no room for the incorporation of non-humans as active elements into safety culture and security analysis (Cooper, 2016; Gilbert et al., 2018; Glendon \& Stanton, 2000; Grote \& Künzler, 2000; Guldenmund, 2007, 2018; Hopkins, 2016; Neisser, 2014; Pidgeon, 1998). Similarly, as argued by Neisser (2014, p. 92), security culture is solely "focused on social practices and institutions". This anthropocentric bias is indebted to sociological works on culture, which have for a long time stressed that: "everything that is not nature has to be seen as culture" (Antonsen, 2009, p. 3). This dominant perspective prevents a proper and more complete understanding of the values and agencies of non-humans (such as dosimeters, physical barriers, security cameras or incident reports) in the dynamic performance of both cultures. Overall, this anthropocentric focus of the research on safety and security cultures may, to some extent, be explained by the following false syllogism: Safety and security cultures both deal with culture and culture deals with humans. Therefore they both deal with humans. The anthropocentricity of research on safety and security cultures represents the second gap this paper addresses.

Concurring with Healy, “a 'safety culture' [or security culture] that is not embodied or reflected in organizational and material realities may prove to be not only unproductive, but counterproductive" (2004, p. 288). However, despite this lack of systematic attention to non-human agents in safety and security cultures, some scholars have included in their thinking ideas about the potential impacts of hardware, physical environment or software - albeit tentatively (Glendon \& Stanton, 2000; Grote \& Künzler, 2000; Guldenmund, 2007, 2000; Naevestad, 2009; Pidgeon, 1998; Yoo \& Lee, 2015). For instance, Yoo \& Lee, in their security culture questionnaire asked employees to what extent guidance documents or training and education programs impact security 
awareness (Yoo \& Lee, 2015). Guldenmund (2000), Grote and Künzler (2000) and Glendon \& Stanton (2000), in their analysis of safety culture, argue in favor of considering both software and hardware. Naevestad acknowledges that research on safety culture "lack[s] a proper conceptualization of the relationship between culture, technology and structure in high-risk organizations" (2009, p. 126). Furthermore, the model of Reniers et al. (2011) opens up the analysis of safety and security cultures to include the impact of technologies and procedures.

These developments are promising, as they enable the much-needed reflection on the potential role of non-humans in safety and security cultures enactment. However, even though several authors plead for a greater integration of non-humans in research around these concepts (Haavik, 2011; Healy, 2004; Le Coze, 2013; Naevestad, 2009; Rollenhagen, 2010), non-human objects and factors - when considered - are still by and large perceived as external influences on culture, rather than appreciated as actors that constitute and actively shape the culture in which they are embedded (Akrich et al., 2013).

Having illustrated the emergence and development of the notions of safety and security cultures, including their roots and contending views and enactments, we now turn to co-production and Actor-Network Theory. As we point out below, these concepts and approaches allow us to address the gaps identified above: the asymmetrical treatment of security culture in relation to safety culture (which raises issues of proper conceptualization, as well as practical issues of efficacy and organization) and the need to consider the role and potential of nonhumans in safety and security contexts.

\section{Bringing co-production and ANT into the safety-security relation}

A relatively limited number of studies have addressed both safety and security cultures in an encompassing manner (Aven, 2007; Dupont \& Reniers, 2010; Gandhi \& Kang, 2013; Hahn, 2011; Hessami, 2004; Khripunov \& Kim, 2008; Kim \& Kang, 2012; Koenick, 2011; Reniers et al., 2011). In order to tackle the gaps of the subordination of security culture to safety culture and the overlooked role of non-humans, we take inspiration from the interdisciplinary field of Science and Technologies Studies (STS) which considers how science and technology affect society - and how society, in turn, affects scientific research and technological innovation. To address the two gaps identified earlier and therefore bringing symmetry in the analysis of both cultures, we specifically rely on the concept of co-production and on Actor Network Theory.

\subsection{Co-production}

Broadly understood, co-production implies that science is not just a force that shapes and changes society, but is in turn shaped by social forces (Latour, 1992; Shapin \& Schaffer, 1985). Rather than a complete theory or model, co-production is an idiom: an invitation to consider how science and technological orders evolve together with the sociopolitical order (representations, identities, discourses, and institutions) in specific contexts (Jasanoff, 2004). Developed by Jasanoff (2004), among others, it sensitizes us to the mutual shaping of technology, science and society, and has proven useful in the study of natural and man-made disasters. In this perspective, technology and society should not be seen as two separate spheres, but rather as interacting components of a complete system, which mutually construct each other. For instance, in her analysis of the evolving relations and the mutual impact between the 1983 Bhopal industrial disaster and law, Jasanoff highlights "the black-boxed relationships of co-production that link the development of material technologies with contextual social practices such as the law" (Jasanoff, 2014, p. 95).

Arguing that material technology is too often analyzed as an independent device disconnected from its environment, Jasanoff proposes to study how it is framed within specific governance and sectorial boundaries.

She speaks of "civic epistemology" to denote "institutionalized preferences for styles of evidence and argumentation that are sustained in a durable community" (Willems, 2014, p. 44). When these implicit styles, codes and frames are made explicit, for instance with controversies and disruptions, it becomes clearer why particular sociotechnical constellations take the forms they do. These controversies reflect a range of "already existing frames within which social actors think and act. Focusing on the effects of such transformative events can bring more clearly into view salient differences" between the cultures of different communities (Willems, 2014, p. 41). The researcher is supposed to analyze the controversial, potentially disruptive, moments when new orders emerge or when existing orders clash. During these episodes, everything is in flux and the discourses are loaded with different justifications and frames.

As it seeks to capture the dynamic co-shaping of two elements, coproduction is well suited for the symmetrical analysis of safety culture and security culture. Security and safety are usually linked to different regulatory and legal frameworks. Co-production draws attention to the potential tensions or collisions arising from the development of specific devices standing at the boundary points between the two cultures. By focusing on the mutual evolution of safety and security elements rather than treating them as isolated entities, it provides a useful lens to examine both concepts in dynamic relation to one another.

\subsection{Actor-network theory}

Actor-Network Theory (ANT) has been developed by scholars such as Akrich, Callon, Latour and Law from the 1980's onwards. It is best understood as an epistemological approach, which asserts that 'the social', originating in the term 'association', is defined by constantly shifting networks of relationships (Latour, 2005; Strum and Latour, 1987). These networks consist of continuously enacted local and contextual interactions between actors, which can be both human and nonhuman. Actors' identities are defined and re-defined through their relationships, which also participate in defining, creating and stabilizing these relations (Strum and Latour, 1987; Callon, 1985).

According to Strum and Latour (1987), humans are "social players actively negotiating and renegotiating what their society is and what it will $b e$ " (p.789). They organize themselves practically by mobilizing various resources, including material forms and technologies (e.g., labels or turnstile gates in an organization). These resources embed norms and values, which allow actors to meaningfully coordinate and negotiate their behaviors, relationships and activities (e.g., what is the chemical in the container and who can enter the building). The institutionalization of such complex processes signifies that negotiations are closed down on the social level: actors who decide to implement these processes acquire "the ability to organize others on a large scale, even when those others are not physically present" (idem, p.793).

ANT provides useful tools and principles for the empirical examination of security and safety cultures' enactment.

First, it suggests that social realities are best understood by following actors (also called actants in ANT vocabulary), both human and nonhuman, and by describing their behaviors and interactions with other humans or non-humans that are part of an actor-network. Different from mainstream sociological approaches, ANT argues that 'the social' is not simply out there, and cannot be explained by relying on predefined concepts or social theories that are then applied to the study at hand (Strum and Latour, 1987). To get a grasp of a particular object, phenomenon or issue, ANT demands to unravel and analyze all relations linking actors with each other as a network. To capture the intricate and complex features of 'enactment', ANT prescribes the methodological precept of generalized symmetry, which means that all entities in a network can and should be described in the same terms. The underlying rationale is that differences between entities are only generated in a living network of relations, and should not be 
presupposed. This approach is empirically determined by following actors in their dealings and relations with others (Latour, 2005).

ANT allows analysts to highlight the interconnections between humans and non-humans and examine the agencies developed by all, including material artifacts such as containers, buildings, and trucks. By avoiding overgeneralizing social patterns, it enables the development of complex, dynamic and localized understandings of the network and the way actors are (re)defined through their interactions.

Second, ANT asserts that the actors interacting in the network may have diverging and incompatible interests. Consequently, the stability of the network is acquired only when interests, stakes, values are aligned (Latour, 1987). This alignment "occurs through a process where the actors' interests are translated (i.e. reformulated, modified, or changed) into more generally agreeable expressions, so that several actors may support the resulting translation" (Aanestad, 2003, p. 7). Some actors tend to occupy central positions with a specific status of spokesperson within the network, or an obligatory passage point (Callon, 1985). This concept enables to detect the actor(s) structuring the network, as they establish an "indispensable channel through which all other actants must pass" (Scoles, 2018). Identifying such actors and the translation process they coordinated is key to understanding the dynamics of safety and security cultures. It also facilitates detecting and tracing the actors interacting within these (safety and security) networks (Heller, 2002). For instance, an evacuation door or turnstile gate is both figurative and literal obligatory passage points, through which all other actors (employees, regulations, badges, etc.) have to pass to interact within the network, whether to evacuate in case of an emergency or to simply enter the premise for their daily work. Therefore, they both enable and constrain others actors' behaviors.

ANT has proven useful to the study of safety and security in domains such as bioterrorism. For instance, Mainz (2008) studied bioterrorism risks through an analysis of anthrax powder in "letter bombs", while Pohler and Schillmeier (2010) examined the agency of the SARS virus. While technically not a work of ANT, Diane Vaughan in her book "The Challenger launch decision", shows how defect rubbers (O-rings) were at the origin of the Challenger space shuttle accident in 1986. She demonstrates how the presence of O-rings in the shuttle was the consequence of, and reinforced, a deviant safety culture inside NASA, which put the safety of the mission at threat (Vaughan, 1996).

These studies highlight that artifacts, technologies and ideas may be considered in relation to human actors. Non-humans develop their own strategies and interact dynamically with humans; they are not to be taken as passive or external objects. In a nutshell, such analyses account for the social relations in which non-humans play an active role, thereby avoiding the pitfall of reducing social issues to human interactions.

\section{Addressing the gaps: Symmetry between and within safety and security cultures}

Both co-production and ANT invite us to question the view that cultures, and 'social' issues more globally, are only about human relations, beliefs, or attitudes. They urge us to account for the mutual shaping of human and non-human worlds (second gap). These approaches move beyond the conventional understanding that culture is a social construct, which can somehow be separated from the technologies that it gives rise to, and which in turn shape it.

Based on this, we argue for bringing symmetry in the analysis of safety and security cultures, by highlighting their mutual influence, as well as within the two cultures, by considering both human and nonhuman actors. Before illustrating how several features of ANT and coproduction can be usefully applied to the study of safety and security cultures, we argue for a theoretical redefining of our understanding of both concepts. Drawing on these STS approaches, safety culture and security culture can be defined as mutually shaping networks that connect humans and non-humans in a given sociotechnical system; which through their interactions co-produce a certain level of protection against harm caused by malevolent agencies for security culture and non-malevolent agencies for safety culture.

In this section, we use two examples to illustrate the application of the two STS approaches for the study of safety and security cultures: the labelling of hazardous material and the "four eyes" principle. These examples lean on the literature and are informed through fieldwork undertaken by the first author in an organization from a hazardous industry.

\subsection{Security dimension of safety devices: Labelling of hazardous materials}

The labelling of hazardous materials implemented in organizations in hazardous industries may illustrate the security implications of safety devices (Keller et al., 1980; Su and Hu, 2008; Wang and Chi, 2003). Such labelling can be understood as a process aimed at storing, classifying, and communicating the location, characteristics and hazards of specific materials. To give an example, a label of a nuclear or a corrosive substance directs attention to interactions with other human or non-human actors in and outside the organization. This label is directly connected to a specific material, container, storage facility, building, intranet platform gathering and sharing features and locations of hazardous materials within the organization, and to employees using or searching for these substances. The label also implies learning, trainings, label glossary categorization procedures, national regulations and shared international standards. Embedded within a global and shared knowledge order, it participates, locks in, and reinforces social ties. An employee manipulating a substance does not have to carry out a full analysis of the material before using it. Through her manipulation of the material following standard operating procedures and received knowledge, she participates in performing the labelling network, whilst relying on a proper enactment from the other actors.

The network of hazardous material labelling therefore performs specific assumptions, values and injunctions through the interactions of humans and non-humans composing the network. For example, a hazardous materials inventory through an intranet platform of an organization, promotes the values of collaboration and transparency by connecting the labels and the storage with different employees of the organization,. These different actors co-produce a whole knowledge order operating on the assumptions, norms and practices of communality and sharing. By making visible and sharing the hazardous elements, their composition and potential risks, a label facilitates the safe manipulation and combination of these materials. In this way, this non-human participates to increase the visibility, the transparency and the prudent use of those materials (IAEA, 2019); thereby contributing to the enactment of safety culture in an organization.

The labelling of hazardous materials also has implications for safety culture. Making labels visible comes with the risk of increasing an organization's vulnerability to malevolent attacks; as does strict adherence to the values of openness, sharing and transparency. Confidentiality and access control, which are key to sustaining an effective security culture, are thus potentially weakened.

\subsection{Safety dimensions of the security principle: The "four eyes" principle}

The "four eyes" principle encountered in some organizations in hazarouds industries (Bodenschatz \& Irlenbusch, 2019; Graff Lambsdorff, 2015; IAEA, 2019; Osaci et al., 2018; Schikora, 2010) can be defined as an "internal control mechanism that requires that any activity by an individual within the organization that involves material risk must be controlled, double checked by a second individual that is independent and competent" (Open Risk Manual, Unknown) ${ }^{2}$. It is set

\footnotetext{
${ }^{2}$ Open Risk Manual: https://www.openriskmanual.org/wiki/Four_Eyes. Principle
} 
up in some (areas of) organizations and is designed to avoid sabotage by implementing control by a peer. These measures, in appearance only connecting two humans with one another, actually involve a multitude of other actors, for instance the legal documents which enforce compliance, the protected areas in which the measures are applicable, the materials, techniques and artifacts manipulated in these protected areas, the fences, walls, doors and gates delimiting these areas, or the inspectors controlling the application of such measures. By tying all those actors together, this principle enforces and facilitates compliant behavior of workers.

In contrast with the previous example of a hazardous material labelling network, this network performs values and injunctions of vigilance, mutual control and possibly, suspicion. It runs counter to, as Schikora highlights (2010), the values of mutual trust, cooperation, self-control and well-being promoted in safety culture thereby possibly creating tensions between safety and security cultures. The "four eyes" principle therefore concomitantly shapes the conditions for a safety culture.

\subsection{Combining co-production and ANT to the analysis of safety and security cultures}

Through these two examples, the combined use of co-production and ANT provides a framework to detect, trace and analyze safety and security cultures networks pertaining to non-humans and their agencies, as well as their underlying values. It thus promotes a symmetrical vision of humans and non-humans as both having agency; that is, as active participants in networks or systems. Safety and security cultures characterize the networks composed of a wide number of actors, which, through their interactions, participate in (re)defining themselves, as well as the overall network to which they belong. In this view, analyzing networks demands safety-security researchers to closely follow actors interacting within these networks and analyzing their interplay with others. Overall, applying co-production and ANT to the empirical analysis of safety and security cultures in organizations permits, as illustrated above, to focus on interactions between actors (both human and non-human) which participate to enact both cultures. It also enables to unveil the values, agencies, strategies they perform. Consequently, it allows to analyze how these two cultures mutually shape each other.

As highlighted in section 2, safety and security cultures are often seen synergetic, two sides of the same coin (Flory, 2013). However, commenting on the global interactions between safety and security, Jore argues that, "although security has become an omnipresent aspect of modern societies, the concept of security in itself has drawn surprisingly little scholarly attention compared to similar concepts such as risk and safety" (2019, p. 157). As it has been insufficiently addressed as a concept on its own, the literature tended to discuss security culture only through the lens of safety by focusing on their similarities. In consequence, the comparison of those two concepts misses a thorough reflection on their contextual and dynamic mutually shaping influences.

As illustrated by the two examples discussed, acknowledging the mutual shaping and influence offers a contextual and dynamic grasp of how safety and security cultures are characterized and how they interact. Our combined approach urges us to analyze safety and security cultures as dynamic interplay; that is, as a mutual shaping within a regulatory, social and institutional setting or context. Through this lens of mutual enactment, safety and security cultures are seen as arrangements which are shaped with and through other elements of culture. They are co-produced, in ways that are generative as well as potentially incompatible or mutually exclusive. To draw a thorough image of safety and security cultures' interplay, tensions also demand to be scrutinized and accounted for, rather than ignored or downplayed. Maintaining that both safety and security cultures can always be enacted simultaneously presents a flaw in the dominant reasoning about safety and security interplay. Overall, despite their important added value in the study of safety and security cultures, co-production and ANT approaches present some limitations and jointly applying them poses some challenges that deserve to be discussed.

As stated above, co-production remains an idiom, an invitation to think about the mutual shaping of scientific, technological elements with societal ones. It remains relatively vague concerning the status of scientific, technological and societal elements. Are technologies and science part of society? Can we analyze technology, science and society symmetrically, by mobilizing the same vocabulary? These questions are often left unanswered by scholars who deploy the co-production idiom.

To that respect, ANT proves useful, as it provides heuristics to identify and explore patterns of co-production within a heterogeneous actor-network. However, the network only exists through interactions and relations within it, which raises the question whether anything exists outside or beyond what the ANT researcher has identified; i.e., the categories $s /$ he is able to trace. There are no 'larger' structural forces which constrain or enable the networks under examination. The main issue for ANT researchers then is to decide the bounds of investigation, be they historical, temporal or spatial, as well as which dimensions of the world are to be taken into consideration. This places a lot of weight on the researcher; it also suggests that important features could escape unnoticed. To give an example, in the case of safety and security cultures, the IAEA guidelines and other international and national regulations may be understood as interconnected actors within the network. However, they could also easily be missed by the researcher if she confines herself to staying within one part of the network, e.g. by focusing only to the interactions within the site of an organization's enclosure.

Second, and in relation to the previous point, ANT seeks to provide an all-encompassing way of seeing (and assembling) the social. Contrary to mainstream sociology approaches, it seeks to equip researchers with all the necessary epistemological, theoretical and methodological tools for a thorough analysis (Latour, 2005). This makes it difficult to combine ANT with other (sociological) approaches which, for their part, insist on drawing analytical and 'real' distinctions between micro and macro levels of analysis for instance; or between elements that many would say are external to the network, such as market forces and capital flows in the global political economy.

Such limitations taken into account, we believe both frameworks are useful and potentially productive. Ideally, the idiom of co-production and ANT approach would be used as sensitizing approaches and as heuristics to improve and further our understanding of safety in relation to security and culture.

\section{Conclusion}

This article seeks to further our understanding of safety, security, and culture based on a literature review of these concepts within the context of organizations in hazardous industries. It identifies two important gaps in our understanding of safety-security: the subordination of security culture to safety culture and the anthropocentricity focus of research on both notions. The paper states the case for more solid and reasoned theoretical foundations to address these two gaps. To this end, it introduces Science and Technology Studies (STS) concepts and approaches, specifically co-production and Actor-Network Theory. Through two concrete illustrations, i.e. the labelling of hazardous material and the "four eyes" principle the article highlights how combining co-production and ANT opens onto a more symmetrical analysis of safety and security cultures in hazardous contexts, such as the nuclear arena.

By focusing on the dynamic interplay between non-human and human elements, and by refraining from making a priori distinctions between procedures, technology, and culture, both co-production and ANT provide a meaningful corrective to anthropocentric perspectives. Contrary to dominant safety and security approaches, they avoid essentialist explanations for events, behaviors, and eventualities. Instead, 
they consider how various elements interact to prompt specific events or behaviors, and explore the circumstances and the assumptions underlying them. ANT is especially relevant as it explicitly proposes a symmetrical approach to humans and non-humans. It also provides multiple tools to detect, trace and draw the network of interactions between actors in safety and security culture networks. Co-production, for its part, is especially useful to designate and consider the mutual shaping and the co-evolution of safety and security cultures. Combining both approaches brings a much-needed symmetry to the analysis of safety and security cultures.

In these ways, they can make a meaningful contribution to further theoretical and empirical research on safety and security cultures in organizations, which will benefit both scholars and practitioners. Providing a conceptual framework which highlights both the interaction between safety and security cultures, and the role played by human as well as non-human actors in their interaction, we hope this article contributes to future empirical explorations of safety and security cultures in organizations.

\section{Acknowledgements}

We would like to extend our sincere thanks to Dr. Robbe Geysmans from the Belgian Nuclear Research Center SCK CEN who helped us a lot in revising this manuscript.

\section{References}

Aanestad, M., 2003. The camera as an actor: design-in-use of telemedicine infrastructure in surgery. Comput. Support. Coop. Work 12, 1-20.

Akrich, M., Callon, M., Latour, B., \& Strum, S. (2013). Sociologie de la traduction. http:// books.openedition.org/pressesmines/1181.

Antonsen, S., 2009. Safety culture and the issue of power. Saf. Sci. 47, 183-191.

Argenti, F., Landucci, G., Spadoni, G., Cozzani, V., 2015. The assessments of the attractiveness of process facilities to terorrist attacks. Saf. Sci. 77, 169-181.

Aven, T., 2007. A unified framework for risk and vulnerability analysis covering both safety and security. Reliab. Eng. Syst. Saf. 92 (6), 745-754. https://doi.org/10.1016/ j.ress.2006.03.008.

Aven, T., Ben-Haim, Y., Boje Andersen, H., Cox, T., Lopez Droguett, E., Greenberg, M., Guikema, S., Kroeger, W., Renn, O., Thompson, K. M., \& Zio, E. (2015). SRA Glossary. Committee on Foundation of Risk Analysis.

Batra, A., Nelson, P., 2012. Safety, safeguards and security in Indian civil nuclear facilities (Scientific Report NSSPI-12-010. Nuclear Security Science and Policy Institute p. 96.

Bernard, B., 2014. Safety culture as a way of responsive regulation: Proposal for a nucelar safety culture oversight model. Int. Nuclear Safety J. 3 (2), 1-11.

Bijker, W.E., Hommels, A., Mesman, J., 2014. Vulnerability in Technological Cultures. New Directions in Research and Governance. The MIT Press.

Bloch, M., 1998. How We Think They Think. Westview Press.

Bodenschatz, A., Irlenbusch, B., 2019. Do two bribe less than one? - An experimental study on the four-eyes-principle. Appl. Economics Lett. 26 (3), 191-195.

Burgess, P.J., Reniers, G.L.L., Ponnet, K., Wim, H., Wim, S., 2018. Socially repsonsible innovation in security. Critical reflections, Routledge New Security Studies.

Callon, M. (1985). Eléments pour une sociologie de la traduction. La domestication des coquilles Saint-Jacques et des marins pêcheurs dans la baie de Saint-Brieuc. L'Année sociologique, 40.

Choudhry, R.M., Fang, D., Mohamed, S., 2007. The nature of safety culture: a survey of the state-of-the-art. Saf. Sci. 45, 993-1012.

Cooper, M.D., 2000. Towards a model of safety culture. Saf. Sci. 36, 111-136.

Cooper, M. D. (2016). Navigating the safety culture construct: A review of the evidence. International Conference on Safety Culture, 36

Cox, S., Cox, T., 1991. The structure of employee attitudes to safety: An European example. Work and Stress 5 (2), 93-106.

Cox, S., Flin, R., 1998. Safety culture: Philosopher's stone or man of straw? Work Stress 12 (3), 189-201. https://doi.org/10.1080/02678379808256861.

Dekker, S. (2011). Drift into failure. From hunting broken components to understanding complex systems. Ashgate Publishing.

Dupont, I., Reniers, G.L.L., 2010. Vergelijkende studie tussen veiligheid en beveiliging: Toepassen van proactieve beschermingsprogramma's bij kritieke infrastructuren. Econ. Management 1-29.

Edwards, J.R.D., Davey, J., Armstrong, K., 2013. Returning to the roots of culture: A review and re-conceptualisation of safety culture. Saf. Sci. 55, 70-80.

Directive 2012/18/EU of the European Parliament and of the Council of 4 July 2012 on the control of major-accident hazards involving dangerous substances, amending and subsequently repealing Council Directive 96/82/EC, Pub. L. No. L 197/1, Official Journal of the European Union 1 (2012).

Flory, D. (2013). Strengthening nuclear safety and security globally a continued international challenge. 1-8.

Fucks, I. (2004). La culture de sûreté selon une démarche compréhensive. Une contribution à la gouvernance des risques dans des systèmes complexes. [Doctoral Thesis]. Centre d'Etude de l'Energie Nucléaire.

Furnham, A., Gunter, B., 2015. Corporate Assessment. Routledge.

Gandhi, S., Kang, J., 2013. Nuclear safety and nuclear security synergy. Ann. Nucl. Energy $60,357-361$.

Geertz, C., 1993. The interpretation of cultures. Basic Books.

Gilbert, C., Journé, B., Laroche, H., \& Bieder, C. (Eds.). (2018). Safety cultures, Safety models. Taking stock and moving forward. Springer Publishing.

Glendon, A.I., Stanton, N.A., 2000. Perspectives on safety culture. Saf. Sci. 34, 193-214.

Graff Lambsdorff, J. (2015). Preventing corruption by promoting trust: Insights from behavioral science (p. 18) [Passauer Diskussionspapiere - Volkswirtschaftliche Reihe]. Universität Passau, Wirtschaftswissenschaftliche Fakultät.

Grote, G., Künzler, C., 2000. Diagnosis of safety culture in safety management audits. Saf. Sci. 34, 131-150.

Guldenmund, F.W., 2007. The use of questionnaires in safety culture research - an evaluation. Saf. Sci. 45, 723-742.

Guldenmund, F.W., 2018. Understanding safety culture through models and metaphors. In: Safety cultures, Safety models: Taking stock and moving forward. Springer Publishing, pp. 21-34.

Guldenmund, Frank. W. (2000). The nature of safety culture: A review of theory and research. Safety Science, 34, 215-257.

Haavik, T.K., 2011. On Components and Relations in Sociotechnical Systems. J. Contingencies Crisis Management 19 (2), 99-109.

Hahn, C., 2011. Intersection between nuclear safety and nuclear security. Our nuclear future, Seoul South Korea, Asan Plenum.

Harsh, S., 2011. Purposeful sampling in qualitative research synthesis. Qualitative Res. J. $11(2), 63-75$.

Harvey, J., Erdos, G., Bolam, H., Cox, M.A.A., Kennedy, J.N.P., Gregory, D.T., 2002. An analysis of safety culture attitudes in a highly regulated environ-ment. Work Stress 16 (1), 18-36.

Haukelid, K., 2008. Theories of (safety) culture revisited-An anthropological approach. Saf. Sci. 46, 413-426.

Healy, S., 2004. A 'post-foundational' interpretation of risk: Risk as 'performance'. J. Risk Res. 7 (3), 277-296. https://doi.org/10.1080/1366987042000176235.

Heller, Chaia, 2002. From Scientific Risk To Paysan Savoir-Faire: Peasant Expertise in the French and Global Debate over GM Crop. Science as Culture 11 (1), 5-37 In press.

Henriqson, E., Schuler, B., Van Winsen, R., Dekker, S.W.A., 2014. The constitution and effects of safety culture as an object in the discourse of accident prevention: a Foucaldian approach. Saf. Sci. 70, 465-476.

Hessami, A.G., 2004. A systems framework for safety and security: the holistic paradigm. Syst. Eng. 7 (2), 99-112. https://doi.org/10.1002/sys.10060.

Hofstede, G., 1994. Cultures And Organizations, Intercultural cooperation and its importance for survival-Software of the Mind, the successful strategist series. Harper Collins Business.

Hollnagel, E. (2014). Safety I, safety II, The past and future of Safety Management. Ashgate Publishing.

Hopkins, A., 2016. Quiet Outrage: The way of a sociologist. Wolters Kluwers.

Hopkins, A., 2018. The use and abuse of "culture". In: Safety cultures, Safety models: Tacking stock and moving forward. Springer Publishing, pp. 35-45.

Huang, D.T., Clermont, G., Sexton, J.B., Karlo, C.A., Miller, R.G., Weissfeld, L.A., Rowan, K.M., Angus, D.C., 2007. Perceptions of safety culture vary across the intensive care units of a single institution. Crit. Care Med. 35, 165-176.

IAEA. (1986). INSAG-1: The Chernobyl Accident. International Atomic Energy Agency.

IAEA. (1991). Safety Culture (Safety Series No 75- INSAG-4). International Atomic Energy Agency.

IAEA, 2001. Measures to improve the security of nuclear materials and other radioactive materials. GOV/2001/41. General Conference IAEA.

IAEA. (2007). Safety Glossary. International Atomic Energy Agency.

IAEA. (2008a). Nuclear Security Culture. International Atomic Energy Agency.

IAEA. (2008b). SCART GUIDELINES. Reference report for IAEA Safety Culture Assessment Review Team (SCART). International Atomic Energy Agency.

IAEA. (2009). Culture de sécurité nucléaire. Collection Sécurité nucléaire de l'AIEA N7. International Atomic Energy Agency.

IAEA, 2016a. IAEA Safety Glossary. Terminology used in nuclear safety and radiation protection. International Atomic Energy Agency.

IAEA, 2016b. Management of the interface between nuclear safety and security for research reactors. International Atomic Energy Agency.

IAEA, 2019. Management of the Interface between Nuclear Safety and Security for Research Reactors. International Atomic Energy Agency.

Jasanoff, S., 2004. States of Knowledge: The Co-Production of Science and the Social Order. Routledge.

Jasanoff, S., 2014. Vulnerability and Development-Bhopal's Lasting Legacy. In: Hommels, A., Mesman, J., Bijker, W.E. (Eds.), Vulnerability in Technological Cultures: New Directions in Research and Governance. The MIT Press, pp. 89-108.

Joly, P.-B., 2015. Governing Emerging Technologies - The need to think out of the (black) box. In: Hilgartner, In S., Miller, C.A., Hagendijk, R. (Eds.), Science and Democracy-Making Knowledge and Making Power in the Biosciences and Beyond. Routledge.

Jore, S. H. (2016). Security culture-A sufficient explanation for a terrorist attack? In T. Bedford \& M. Revie, Risk, Reliability and Safety: Innovation Theory and Practice (pp. 467-474). Taylor \& Francis Group.

Jore, S. H. (2017). Safety and security- Is there a need for an integrated approach? In L. Walls, M. Revie, \& T. Bedford, Risk, Reliability and Safety: Innovating Theory and Practice (pp. 852-859). Taylor \& Francis Group.

Jore, S.H., 2019. The conceptual and scientific demarcation of security in contrast to safety. European J. Security Res. 4, 157-174. 
Keesing, R.M., 1987. Anthropology as interpretive quest. Current Anthropology 28, 161-176.

Keesing, R. M. (1994). Theories of culture revisited. In R. Borofsky, Assessing cultural anthropology: Vol. Vol. XIX (p. 566s). McGraw-Hill.

Keller, L.W., Schaper, K.L., Johnson, C.D., 1980. A hazardous materials identification system for the coatings and resins industry. American Industrial Hygiene Association Journal 41 (12), 901-907 In press.

Khripunov, I., Kim, D., 2008. Time to think safety and security. Korean Times. http:// www.koreatimes.co.kr/www/news/opinon/2011/08/137 92394.html.

Kim, D., Kang, J., 2012. Where nuclear safety and security meet. Bull. Atomic Scientists 68 (1), 86-93.

Koenick, S. (2011). Safety and Security Interface. International Atomic Energy Agency.

Kono, T., 1990. Corporate culture and long-range planning. Long Range Plan. 23 (4), 9-19. https://doi.org/10.1016/0024-6301(90)90148-W.

Krackhardt, D., Kilduff, M., 1990. Friendship patterns and culture: the control of organization diversity. American Anthropologist 92 (1).

Latour, B., 1987. Science in Action: How to Follow Scientists and Engineers through Society. Harvard University Press.

Latour, B. (1992). Where are the Missing Masses? The Sociology of a Few Mundane Artifacts. In W. E. Bijker \& J. Law, Shaping Technology/Building Society: Studies in Sociotechnical Change (pp. 225-258). MIT Press.

Latour, B., 2005. Reassembling the Social: An introduction to Actor-Network Theory. Oxford University Press.

Le Coze, J.C., 2013. New models for new times. An anti-dualist move. Safety Sci. 59, 200-218.

Le Coze, J.C., 2019. How safety culture can make us think. Saf. Sci. 118, 221-229.

Lee, T., \& Harrison, K. (2000). Assessing Safety Culture in Nuclear Power Stations. Safety Science, 34(1-3), 61-97. https://doi.org//10.1016/S0925-7535(00)00007-2.

Lundberg, C.C., 1990. Surfacing organisational culture. J. Managerial Psychology 5 (4), $19-26$.

Mainz, J., 2008. In: Relationalität und räumliche dynamik von risiken-Ein bioterroristisches szenario aus der perspektive der actor-network theory. Spektrum, pp. 411-419.

Malcolmson, J. (2009). What is security culture? Does it differ in content from general organisational culture? 361-367. https://doi.org/10.1109/CCST.2009.5335511.

Martin, J. (1985). Can organizational culture be managed? In P. J. Frost, Organizational Culture (p. 419 s). Sage Publications.

Naevestad, T.-O., 2009. Mapping Research on culture and Safety in High-Risk Organizations: Arguments for a Sociotechnical Understanding of Safety Culture. J. Contingencies Crisis Management 7 (2), 126-136.

Neisser, F.M., 2014. "Riskscapes" and risk management-Review and synthesis of an actor-network theory approach. Risk Management 16 (2), 88-120.

OECD/NEA/FSC. (2013). Stakeholder Confidence in Radioactive Waste Management - An Annotated Glossary of Key Terms. OECD Nuclear Energy Agency.

Open Risk Manual. (Unknown). Four eyes principle [Collaborative website]. Open Risk Manual. https://www.openriskmanual.org/wiki/Four_Eyes_Principle.

NRC, 2018. Safety culture policy statement. NUREG/BR-500, Rev. 4. Nuclear Regulatory Commission In press.

Osaci, M., Cristea, A.D., Ghuzan, D., Berdie, D.A., 2018. SAP authorization based on the four eyes principle. Int. J. Eng. 26, 43-46.

Pidgeon, N., 1991. Safety culture and risk management in organizations. J. Cross Cult.
Psychol. 22 (1), 129-140.

Pidgeon, N., 1998. Safety culture: key theoretical issues. Work Stress 12, 202-216.

Pohler, W., \& Schillmeier, M. (2010). Ein globales risikoereignis. In M. Holzinger, S. May, \& W. Pohler, Weltrisikkeggesellscheft als Ausnahmezustand (pp. 121-151). Velbrück Wissenschaft.

Reason, J., 1998. Achieving a safe culture: theory and practice. Work Stress 12 (3), 293-306.

Reniers, G.L.L., Cremer, K., Buytaert, J., 2011. Continuously and simultaneously optimizing an organization's safety and security culture and climate: The Improvement Diamond for Excellence Achievement and Leadership in Safety \& Security (IDEAL S\& S) model. J. Cleaner Prod. 19, 1239-1249. https://doi.org/10.1016/j.jclepro.2011. 03.002 .

Richter, A., Koch, C., 2004. Integration, differentiation and ambiguity in safety cultures. Saf. Sci. 42, 703-722.

Rochlin, G.I., 1999. Safe operation as a social construct. Ergonomics 42 (11), 1549-1560. https://doi.org/10.1080/001401399184884.

Rollenhagen, C., 2010. Can focus on safety culture become an excuse for not rethinking design of technology? Saf. Sci. 48, 268-278.

Schein, E.H., 1985. Organizational Culture and Leadership 14 Jossey-Bass Publishers.

Schikora, J., 2010. Bringing the four-eyes-principle to the lab. Experim. Tests Theories Inst. D13-V2, 58 .

Schnieder, L., Schnieder, E., \& Ständer, T. (2009). Railway Safety and Security - Two Sides of the Same Coin? ! International Railway Safety Council.

Scoles, J., 2018. Researching 'messy objects': How can boundary objects strengthen the analytical pursuit of an actor-network theory study? Studies Continuing Education 40 (3), 273-289. https://doi.org/10.1080/0158037X.2018.1456416.

Shapin, S., Schaffer, S., 1985. Leviathan and the air-pump: Hobbes, Boyle, and the experimental life. Princeton University Press.

Slovic, P., 1992. Perception of risk: Reflections on the psychometric paradigm. In: Krimsky, In S., Golding, D. (Eds.), Social theories of Risk. Praeger Publishers, pp. $117-152$.

Strum, S.S., Latour, Bruno, 1987. Redefining the social link: from baboons to humans. Soc. Sci. Inform. 26 (4), 783-802. https://doi.org/10.1177/053901887026004004. In press.

Su, Teh-Sheng, Hu, I-Yuang, 2008. Perception towards chemical labeling for college students in Taiwan using Globally Harmonized System. Safe. Sci. 46 (9), 1385-1392. https://doi.org/10.1016/j.ssci.2007.09.002. In press.

The Hague Nuclear Security Summit. (2014). Communiqué.

Tompson, P., Mchugh, D., 2002. Work Organisations. Palgrave.

Vaughan, Diane, 1996. The Challenger Launch Decision. Risky technology, culture and deviance at NASA. The University of Chicago Press, Chicago and London, pp. 1-575 In press.

Wang, An-Hsiang, Chi, Chun-Cheng, 2003. Effects of hazardous material symbol labeling and training on comprehension according to three types of educational specialization. Int. J. Ind. Ergon. 31 (5), 343-355. https://doi.org/10.1016/S0169-8141(02) 00236-6. In press.

Willems, W., 2014. How to do things with knowledge: An interview with Sheila Jasanoff. Krisis- J. Contremp. Philosophy 2, 40-46.

Yoo, H., Lee, J.-H., 2015. Results of nuclear security culture survey on personnel at nuclear power plants. Ann. Nucl. Energy 85, 398-402. 